\title{
Kant's Original Space and Time as Mere Grounds for Possibilities
}

\author{
Thomas Raysmith \\ PhD candidate at Humboldt-Universität zu Berlin \\ Emails: raysmitt@hu-berlin.de, t.h.raysmith@gmail.com
}

\begin{abstract}
In the Critique of Pure Reason Kant appears to make incompatible claims regarding the unitary natures of what he takes to be our a priori representations of space and time. I argue that these representations are unitary independently of all synthesis and explain how this avoids problems encountered by other positions regarding the Transcendental Deduction and its relation to the Transcendental Aesthetic in that work. Central is the claim that these representations (1) contain, when characterized as intuitions and considered as prior to any affections of sensibility, only an infinitude of merely possible finite spatial and temporal representations, and (2) are representations that are merely transcendental grounds for the possibilities for receiving or generating finite representations in sensibility that are determined (immediately, in the case of reception) by means of syntheses that accord with the categories.
\end{abstract}

Keywords: space and time; Transcendental Aesthetic; Transcendental Deduction; form of intuition; formal intuition; pure intuition; B160-1; metaphysical space; synthesis

In the Critique of Pure Reason (CPR), Immanuel Kant appears to make incompatible claims regarding the unitary natures of what he takes to be our a priori representations of space and time. ${ }^{1}$ On the one hand, some of his claims appear to imply that, as unitary, these representations are produced by means of some kind of synthesis. On the other hand, some of his claims appear to imply that these representations must be given to us independently of any synthesis. It is not possible to simply ignore the seeming incompatibility between these claims. For, whether one takes these representations of space and time to be produced by means of synthesis plays a direct role in how one understands the CPR's Transcendental Deduction of the Pure Concepts of the Understanding (TD) and its relation to the Transcendental Aesthetic (TA) section of that work. In this article, I will examine several positions prominent in the literature today, on how to resolve the apparent interpretative dilemma, highlighting the problems they each face. I will then present my own position, according to which our a priori representations of space and time are unitary independently of all synthesis, and explain how it avoids the problems encountered by the other positions examined. 
Central to my position is the claim that our a priori representations of space and time (1) contain, when characterized as intuitions and considered as prior to any affections of sensibility, only merely possible finite spatial and temporal representations, and (2) are representations that are merely the transcendental grounds for the possibilities for receiving or generating finite representations in sensibility determined (immediately, in the case of reception) by means of syntheses that accord with the categories. ${ }^{2}$

\section{The problem}

In the TA - more specifically, in the Metaphysical Expositions (MEs) of space and time - Kant makes the following claims related to the unitary natures of our a priori representations of space and time (hereafter, when referring to these representations as discussed in the TA, I will use the phrase 'original space and time'):

Space is not a discursive or, as is said, general concept of relations of things in general, but a pure intuition. For, first, one can only represent a unitary space (nur einen einigen Raum vorstellen), and if one speaks of many spaces, one understands by that only parts of one and the same unique space (nur Teile eines und desselben alleinigen Raumes). And these parts cannot as it were precede (vorhergehen) the unitary all-encompassing (einigen allbefassenden) space as its components (from which its composition would be impossible), but rather are only thought in it. It is essentially unitary (einig); the manifold in it, thus also the general concept of spaces in general, rests merely on limitations (Einschränkungen). (A24-5/B39, translation modified)

Time is no discursive or, as one calls it, general concept, but a pure form of sensible intuition. Different times are only parts of one and the same time (nur Teile eben derselben Zeit). That representation, however, which can only be given through a single object, is an intuition. ... [E]very determinate magnitude of time is only possible through limitations of an underlying unitary time (Einschränkungen einer einigen zum Grunde liegenden Zeit). (A31-2/B47-8, translation modified)

Later in $C P R$, in the TD, Kant revisits the issue of the unitary natures of space and time:

But space and time are represented a priori not merely as forms of sensible intuition, but also as intuitions themselves (which contain a manifold), and thus with the determination of the unity (Einheit) of this manifold in them (see the Transcendental Aesthetic).*

* Space, represented as object (Gegenstand) (as is really required in geometry), contains more than the mere form of intuition, namely the comprehension (Zusammenfassung) of the manifold given in accordance with the form of sensibility in an intuitive representation, so that the form of intuition merely gives the manifold, but the formal intuition gives unity of the representation. In the Aesthetic I ascribed this unity (Einheit) merely to sensibility, only in order to note that it precedes (vorhergehe) all concepts, though to be sure it presupposes (voraussetzt) a synthesis, which does not belong to the senses 
but through which all concepts of space and time first become possible. For since through it (as the understanding determines the sensibility) space or time are first given as intuitions, the unity of this a priori intuition belongs to space and time, and not to the concept of the understanding ... (B160-1 incl. note)

In order to bring out the tension between these passages, it is helpful to refer to Kant's definition of the term 'synthesis'. In its most general form, synthesis is the combination (Verbindung) of several representations. In relation to intuitive representations, synthesis is an action by which a manifold of intuition is 'gone through, taken up, and combined in a certain way' (A77/B102). Kant calls this action 'synthesis' in order 'to draw attention to the fact that we can represent nothing as combined in the object without previously having combined it ourselves' (B130). Specifically, this means, as Kant puts it, that

the combination (conjunction) of a manifold in general can never come to us through the senses, and therefore cannot already be contained in the pure form of sensible intuition; for it is an act of the spontaneity of the power of representation (ein Actus der Sponteneität der Vorstellungskraft), and, since one must call the latter understanding (Verstand) all combination, whether we are conscious of it or not ... is an action of the understanding. (B129-30)

The problem readers of Kant, after reading these passages, are forced to grapple with is how to think the unity of the representation given by the formal intuition of B160$1 \mathrm{n}$. as 'preceding all concepts' and 'belonging to space and time' and yet 'presupposing a synthesis', which is an 'action of the understanding' - the faculty of the 'spontaneity of concepts' (A50/B74). In order to resolve this problem, we must answer the following interpretative question: when Kant states, at B160-1n., that the unity of the representation given by the formal intuition of space (the same goes for time) 'presupposes a synthesis' - a synthesis 'through' which 'space or time are first given as intuitions' is he saying that the unities of original space and time are produced by synthesis? Borrowing terms from Colin McLear (2015), I will call those who answer this question in the affirmative intellectualists and those who answer in the negative sensibilists. ${ }^{3}$ I will first discuss several variants of intellectualism and highlight some of the problems they face. ${ }^{4}$

\section{Categorial intellectualism}

In order to discuss intellectualism, I must first put the spotlight on its motivations. This is due to there being no explicit claim at B160-1n. that the unity of the representation given by the formal intuition is produced by synthesis, and thus no explicit claim that original space and time are produced by synthesis (assuming, as the intellectualist does, that the two claims come to the same). Indeed, Kant's statement that this unity 'belongs to space and time' would seem to count against such a claim. This is for the reason that it seems reasonable to assume that the space and time Kant is referring to here are original space and time and, as already noted, Kant clearly states that the combination (conjunction) of a manifold in general can never come to us 
through the senses, and therefore cannot already be contained in pure form of sensible intuition' (B129). What, then, is the motivation of the intellectualist?

Kant makes it clear, both in the TA and later in $C P R$, that he takes original space and time as unitary representations to be intuitions (cf. B40, A32/B48, A42/B60, B136n.). Additionally, he makes it clear that he regards them as intuitions that, in some sense, contain (enthalten) manifolds of intuitions as their parts (Teile) (cf. A25/B39, A31-2/ B47-8, B136n.). With this in mind, it is possible to draw out some initial motivation for an intellectualist position. Note that Kant also makes the following statements:

The I think must be able to accompany all my representations ... Thus all manifold of intuition has a necessary relation to the I think in the same subject in which the manifold is to be encountered. (B132)

A manifold that is contained in an intuition that I call mine is represented as belonging to the necessary unity of self-consciousness through the synthesis of the understanding, and this takes place by means of the category. (B144)

The same function that gives unity to the different representations in a judgement also gives unity to the mere synthesis of different representations in an intuition, which, expressed generally, is called the pure concept of the understanding. The same understanding, therefore, and indeed by means of the very same actions through which it brings the logical form of judgement into concepts by means of the analytical unity, also brings a transcendental content into its representations by means of the synthetic unity of the manifold in intuition in general .... (B104-5)

Considering the first two passages first, it is easy to understand how one might conclude that the unities of original space and time are produced by a specific type of synthesis, namely, some kind of categorial synthesis - that is, a synthesis governed by the categories. ${ }^{5}$ Given that original space and time are intuitions (thus, representations) that contain manifolds, we can say, from the first passage, that they must have a necessary relation to the I think - meaning they must, at the very least, be able to be thought as mine. From this, it is possible to interpret the second passage as telling us that in order for a manifold to be contained in an intuition I call mine, it must be represented, by means of categorial synthesis, as belonging to the unity of selfconsciousness. Noting also that 'the function that gives unity to the different representations in a judgement' is a function of synthesis for Kant (cf. A78-9/B104-5, B141-3), then, so long as one reads 'the pure concept of the understanding' as 'the category', ${ }^{6}$ it is possible to read the third passage above as lending support to this conclusion. ${ }^{7}$ That is, it is possible to read Kant as claiming that the function of categorial synthesis produces original space and time by giving unity to the manifolds of intuition in original space and time, just as it gives synthetic unity to manifolds of intuition in general. ${ }^{8}$

\section{Problems with categorial intellectualism}

The most devastating arguments against the categorial brand of intellectualism are now well rehearsed in the literature (cf. Messina 2014, McLear 2015, Onof and 
Schulting 2015, Williams 2018). One argument is that categorial intellectualism does not cohere well with Kant's text. As already noted, Kant states at B160-1n. that the unity of representation given by the formal intuition 'precedes all concepts'. Claiming that this unity is produced by a synthesis governed by the categories would seem to be in direct contradiction with this claim.

Another argument against categorial intellectualism focuses on the particular outputs of category-guided syntheses of manifolds of intuition. In the TD, Kant draws a distinction between the synthesis of the manifold of intuition that 'would be thought in the mere category', which he calls synthesis intellectualis, and what he calls 'figurative [synthesis]' (synthesis speciosa), which is the 'synthesis of intuitions [pure or empirical], in accordance with the categories' (B151-2). Without delving into this distinction further, it can be said that any category-guided synthesis of a manifold of intuition would have to be a case of figurative synthesis. This is problematic for the categorial intellectualist because, as James Messina notes, 'Kant seems to be defining figurative synthesis by claiming that it results in determinate [spatial or temporal] intuitions' (2014: 20; my emphasis), determinate spaces and times - that is, intuitions determined with respect to spatial or temporal predicates (cf. B138 and B154). ${ }^{9}$ Yet Kant is quite explicit, in CPR and elsewhere, that original space and time are indeterminate in this sense (cf. B154 and P, 4: 321).

Not only this, determinate spaces and times are also what Kant considers as 'parts' (Teile) of original space and time. And, as is made clear in the two passages from the TA with which I began this article, Kant regards parts of original space and time as made possible by 'limitations' of the original space and time that precede them. That is, he takes there to be a metaphysical priority of original space and time over the determinate spaces and times that are their parts, such that the former make the latter possible (cf. A438/B466).

The categorial intellectualist position would appear to run counter to these statements. It takes the unities of original space and time to be produced by categorial synthesis. Because such synthesis must be figurative synthesis - which Kant appears to define as resulting in determinate spatial or temporal intuitions that can only be parts of original space and time - the categorial intellectualist position would, then, appear to imply that the parts of original space and time have metaphysical priority over original space and time.

This issue is only compounded when one also takes into account Kant's pronouncements in the TA that original space and time are both infinite (unendliche) (A25/B39, A32/B47). ${ }^{10}$ For, if the unities of original space and time were produced by syntheses of their parts, this would, as McLear states, entail that our conception of space [but the same goes for time] as an infinite whole would be logically constructed from our grasp of the discrete spaces composing it' (2015: 88). ${ }^{11}$ Yet the construction of such a conception appears to be impossible for finite rational creatures like us within Kant's Critical philosophy.

\section{Non-categorial intellectualism and its problems}

In response to these problems, but still wishing to hold on to the claim that original space and time, as intuitions, are produced by figurative synthesis, the intellectualist might opt for a variant of non-categorial intellectualism. For instance, one might 
choose to claim that Kant does not mean to define all figurative syntheses as syntheses resulting in determinate intuitions, but only figurative syntheses involving the categories. This leaves open the possibility that there may be a particular species of figurative synthesis that is not governed by the categories and does not result in determinate intuitions. Such a claim could result in positions like those elaborated by e.g. Michael Friedman $(2012,2020)$ and Béatrice Longuenesse $(1998,2005)$, both of whom, in different ways, have argued that original space and time, as the formal intuitions mentioned at B160-1n., are produced by pre-conceptual, and thus precategorial, figurative syntheses effected on sensibility. ${ }^{12}$ In recent elaborations of their positions, both Friedman and Longuenesse have claimed that it is the original synthetic unity of apperception (OSUA) that is in some way responsible for the figurative synthesis that produces original space and time as formal intuitions.

Friedman writes:

the figurative synthesis that unifies space and time as formal intuitions is preconceptual and thus precategorial - and ... it proceeds directly from the transcendental unity of apperception [i.e. the OSUA] without relying on any particular category. (2020: 218, n. 25; see also 2012: 245-9)

\section{And Longuenesse writes:}

What I understand Kant as saying is this: the unity of apperception [OSUA] ... generates the representation of the unity and unicity of space and time ... prior to any specific synthesis according to the categories ... (2005: 36)

The OSUA 'is that self-consciousness which ... produces the representation I think, which must be able to accompany' all my (other) representations (B132). Moreover, it is through the OSUA alone that a manifold of actual intuition can be unified in a single intuition (cf. B143), and it is that unity through which all of the manifold given in an intuition is united in a concept of the object' (B139). For these reasons, the OSUA is 'something under which every intuition must stand in order to become an object for me' (B138) - where an object here is something I can represent as unified under a concept in judgement. The OSUA is, therefore, 'the supreme principle of all use of the understanding' (B136) for Kant. The reason non-categorial intellectualists are wont to appeal to the OSUA is that Kant states that its synthetic unity 'precedes all concepts of combination (Verbindung) a priori' (B131). That being said, he also makes clear that the OSUA can only be thought by means of a manifold given in intuition being synthesized, and thus brought under the OSUA, by the logical functions for judgement (see B135 and B143), which the categories 'express in a general way' (cf. B105).

Just as with categorial intellectualist positions, the intellectualist positions of Friedman and Longuenesse face serious problems. ${ }^{13}$ The first has been brought into sharp relief by McLear (2015: \$2.1). ${ }^{14}$ First, note that Kant describes figurative synthesis as an action of the imagination (Einbildungskraft) (B151-2). Second, note that he defines the imagination as 'an effect (Wirkung) of the understanding on sensibility' (B152). Third, note that he holds that, in all its activities, our (finite) understanding must always proceed in the direction of parts to wholes (CJ, 5: 251-4, 407; see also 
B72). The means by which it does so is synthesis, the action that defines the understanding as the faculty of spontaneity (cf. A51/B75 and A77/B102). By synthesis, the understanding goes through the parts, takes them up and combines them in certain ways into wholes (cf. A77/B102). Since the imagination is equated with an effect of the understanding, and since the understanding, in all its activities, must always proceed from parts to whole, any representation produced by the figurative synthesis of the imagination will be one in which the parts precede and make possible the whole. Such a representation cannot, then, be identified with original space or time.

In response to this problem, Jessica Williams has recently offered an alternative for those still wishing to remain on the side of intellectualism. According to her proposal, the OSUA, when it is 'realized in relation' to a spatio-temporal manifold (2018: 76), is the subject's consciousness of her own 'capacity for affecting [sic] unity' of all manifolds given in sensibility within a unitary space and/or only time (2018: 75). And it is through the subject's consciousness of this capacity that the representations of original space and time, as formal intuitions, are produced..$^{15}$ The original synthesis of original space and time, as formal intuitions, is thus 'not [to be thought] as a synthesis or combination of parts, but as the synthesis of the understanding and sensibility themselves, which grounds the identity of apperception and the unity of space and time' (Williams 2018: 75).

While Williams' account of the unity of original space and time, as formal intuitions, avoids depicting this unity as produced by any particular figurative synthesis, it addresses the problem Friedman and Longuenesse are burdened with at the wrong level. This problem is not simply that their accounts involve the claim that the unity of original space and time, as formal intuitions, is produced by figurative synthesis. It is, rather, what such a claim entails, namely, that the unity at issue is one with respect to which the parts precede the whole. And Williams' account entails the same. For, according to this account, the OSUA is the subject's consciousness of her capacity for effecting unity upon all spatio-temporal manifolds of intuition by means of synthesis. Any unity a subject effects on such a manifold by means of synthesis, however, can only be one wherein the parts precede the whole. Accordingly, the representations of original space and time, as formal intuitions, which a consciousness of the capacity for effecting such a unity is supposed to produce, could only be representations of unities brought about by syntheses of their parts. Williams attempts to get around this problem by stating the following:

While there is a sense in which it is obviously correct to say that synthesis proceeds from parts to whole, in that it involves the 'running through and gathering together' of the manifold of intuition, there is nevertheless an aspect of the consciousness involved in all acts of synthesis that has a whole-part priority, in that any act of synthesis involves the consciousness of the fundamental unity of consciousness (and thus experience) with respect to which any particular determination must be made. (2018: 80)

Instead of resolving the issue, however, this passage magnifies it. The problem is located precisely not on the side of the aspect of the consciousness of the unity of consciousness (and thus experience). The problem is located on the side of the aspect 
of the representations - original space and time as formal intuitions - produced by the consciousness of the unity of consciousness (and thus experience). These are the representations that cannot have a part-whole priority. But they remain, for Williams, representations of unities that a subject has the capacity to effect by means of synthesis, i.e. unities with a part-whole priority.

I shall now consider some variants of sensibilism prominent in the literature.

\section{Prominent variants of sensibilism and their problems}

For the most part, sensibilists grant to original space and time all the features Kant attributes to them in the MEs of space and time as belonging to them entirely independently of any synthesis. ${ }^{16}$ Thus, for the most part, they claim that original space and time, independent of any synthesis, are unitary, unique, infinite and whole a priori representations that are metaphysically prior to parts of space and time. Beyond this, however, sensibilists disagree on the best way to cash out the additional aspects of their positions - including, significantly, those that relate to how to read the note to B160-1.

One way to elaborate a sensibilist position is to argue that the formal intuition and the unity of representation it gives, discussed at B160-1n., are not to be equated in any way with original space and time and their unitary natures. Such an argument has been made by Colin McLear (2015), Andrew Roche (2018) and Daniel Sutherland (2005). They claim that when Kant speaks of the formal intuition at B160-1n., he is really speaking of a determinate spatial intuition (and, by extension, a determinate temporal intuition). They then argue that, in the note, Kant is stating that it is this determinate spatial intuition (and mutatis mutandis the determinate temporal intuition), not original space, that is produced by synthesis. ${ }^{17}$ In support of this argument, one could point to the fact, as McLear does (2015: 90), that at the beginning of B160-1n., Kant writes of 'Space, represented as object (as is really required in geometry)' (B160).

I do not agree that Kant is equating a determinate space with the formal intuition of B160-1n..$^{18}$ After introducing the notion of the formal intuition that 'gives unity of the representation' (B160n.), Kant states that '[i]n the Aesthetic [i.e. the TA] I ascribed this unity merely to sensibility' (B160-1n.). Kant, then, appears to be explicitly equating the unity given by the formal intuition with the unity of original space (and time).$^{19}$ Moreover, as Messina has noted, ' $[\mathrm{t}]$ here is a good deal of evidence to suggest that the pure intuition [of the TA] and formal intuition are synonyms' (2014: 19). One piece of evidence, besides that just noted is, as Messina highlights (ibid.), that B1601n. apparently builds on another note at B136, in which Kant discusses space and time as intuitions and makes it clear, by referring the reader back to the TA, that he has the pure intuitions of original space and time in mind. Beyond this, pointing to the mention of space represented as object does not support equating the formal intuition with a determinate space. For, as I will explain below, Kant has a notion of object that does not require the object to be produced by figurative synthesis. If this is the notion of object at play at the beginning of B160-1n., as I will claim it is, then it does not imply that the object is a determinate space.

In response to all this, the sensibilist may choose to adopt the position presented by Messina. Messina maintains that the formal intuition of B160-1n. is the original 
space of the TA (presumably he would say the same with regard to original time). Furthermore, he maintains that it is a synthetic unity, analogous to 'God's representation of the world as a synthetic universal' (explained by Kant at CJ, 5: 407) (Messina 2014: 23). The details of such a representation are not important here. What is important is Messina's statement that '[w] hat makes this representation [i.e. the formal intuition of space] synthetic is not that it is the result of synthesis ... [W] hat makes this representation synthetic is both that it is a whole (in Kant's strict sense [of having wholepart priority]) and that it makes possible a combination of the manifold contained within it' (ibid.). In relation to our finite discursive understanding, Messina continues, 'the particular sort of necessary combination that our formal intuitions make possible is synthesis', specifically, figurative synthesis (ibid.). What Messina is aiming to secure here, with a view to the viability of the TD, is the claim that all manifold of intuition is able to be and only able to be unified by means of figurative synthesis, i.e. synthesis that accords with the categories.

Messina regards original space, as formal intuition (the same goes for original time), as containing a manifold of actual intuition that is, as first given, not yet delimited or determined. In his attempt to ensure that this manifold can be unified by means of figurative synthesis, he claims that the synthetic unity of the formal intuition of original space 'is necessitated by the OSUA' (2014: 23). On the surface, this sounds like a claim that could support a viable reading of the TD. Yet the way Messina cashes out his notion of 'necessitated by' renders this claim ad hoc and, worse, renders Kant's TD a non-sequitur. Messina's statement that the synthetic unity of the formal intuition of original space (and time) is 'necessitated by' the OSUA means: if discursive understandings (i.e. the understandings we have) are to be able to synthesize any representations, then the formal intuition of original space (and time) is required to be a synthetic unity (cf. Messina 2014: 24-5). Without ruling out all positions that present original space (and time), as formal intuition, as not being a synthetic unity, including my own, however, the consequent here is ad hoc. For this reason, one cannot conclude from this 'necessitated by' claim, as Messina would have Kant do in the TD, that the formal intuition of original space (and time) is a synthetic unity.

Another alternative for sensibilists is to go down the path laid by Christian Onof and Dennis Schulting and claim that the unity of the formal intuition does require a synthesis and is the representation of original space (or time), but only 'insofar as it is taken as a unity' by the understanding (2015: 29). Without this synthesis, according to Onof and Schulting, original space (or time) is characterized as just the form of intuition, which merely gives a manifold of spatial intuition. Characterized only as the form of intuition, original space (or time), is a 'unicity' - where being a unicity is to have the combined features of singularity (being the only and unique space (or time) one can represent), metaphysical priority over its parts, and infinitude (cf. Onof and Schulting 2015: 15). Original space (or time) characterized only as form of intuition does not, then, have the (synthetic) unity it comes to have when the understanding takes it as, when it is characterized as, formal intuition. ${ }^{20}$

On this account, original space, characterized as form of intuition, is what first gives a subject a manifold of actual spatial intuition. Furthermore, according to this account, 'the unicity of space defines a structure of space that characterizes the relations between regions of space' (Onof and Schulting 2015: 15). The upshot of this is 
that manifolds of empirical spatial intuition and, thereby, appearances (where an appearance is 'the undetermined object of an empirical intuition', A20/B34) are regarded as having their structures defined by the unicity of space, meaning they are regarded as being first given in a manner such that they do not have unities produced by any synthesis that would accord with the categories. The problem here is that this result runs counter to what Kant appears to take himself to be proving in the TD, namely, that the categories have a priori objective validity precisely because empirical intuitions and, thereby, appearances are first given in a manner such that they do have unities produced by syntheses that accord with the categories (cf. A84/ B116ff.). In explaining what he aims to achieve in the second step of the TD of the B edition, ${ }^{21}$ Kant writes:

In the sequel (\$26) it will be shown from the way in which empirical intuition is given in sensibility that its unity can be none other than the one the category prescribes to the manifold of a given intuition in general according to [the logical function for judging]. (B144-5; my emphases) $)^{22}$

I do not claim that this makes it impossible for Onof and Schulting to give a compelling account of the TD, but only that it is an issue that needs to be addressed. My own sensibilist position, which I will now outline, does address this issue. It does so, however, by means of dropping two commitments integral to the position of Onof and Schulting, namely, the commitment to the form of intuition giving a manifold of actual representation and the commitment to the unity of the formal intuition requiring a synthesis.

\section{Key to a new proposal: original space and time as devoid of limits}

My sensibilist position takes its bearing from the combination of the following two claims made by Kant: (1) space and time are unitary (einigen) pure intuitions that are metaphysically prior to their parts, in that they make the latter possible; (2) the parts of space or time 'rest on' or 'are only possible through' the limitations (Einschränkungen) of a unitary pure intuition of space or time (A25/B39, A31-2/ B47-8, A42/B60). These two claims, taken together, mean that the unitary intuitions of space and time are, for Kant, metaphysically prior to all their limitations. I take this to mean that, not even in some conceptually undetermined sense, are any limits or limited (finite) spatial or temporal representations given in the unitary intuitions of space and time, insofar as they are considered as prior to any affections of sensibility. Thus, I suggest the infinitude (Unendlichkeit) of the unitary intuitions of space and time be understood in the specific sense of 'containing no finitude', 'containing no limits'. This is the sense in which I read Kant's claim that the unitary intuition of time is given as unlimited (uneingeschränkt) (A32/B48). A line, for contrast, may be infinite (or at least potentially infinite). But it is, for Kant, comprised of points, which are places of the unitary intuition of space's limitation (A169/B211). For this reason, limits and finitude (of space) are still given in the (potentially) infinite line.

As this explanation stands, however, it does not sufficiently distinguish my sensibilist position from those of e.g. Onof/Schulting and Messina. It begins to be so distinguished by means of a consideration of Kant's notions of 'form of intuition' and 
'formal intuition'. Recall that Messina claims original space, as formal intuition, contains a manifold of actual representation. Recall also that Onof and Schulting claim original space, characterized as only form of intuition, gives a manifold of actual representation. I deny both these claims. I maintain, as Onof and Schulting do, that 'form of intuition' and 'formal intuition' both refer to space (or time) as discussed in the TA (i.e. original space (or time)) - more on this momentarily - but that Kant's discussion of space (and time) in the TA 'is indifferent between [space's (and time's)] characterization as form of intuition or formal intuition' (Onof and Schulting 2014: 294). However, I deny that original space (or time), characterized as either form of intuition or formal intuition, and considered as prior to any affections of sensibility, contains or gives any manifold of actual spatial (or temporal) intuition, which would be available to be delimited or, so to speak, 'carved up'. Where actual spatial and temporal manifolds are concerned, I regard original space and time, considered as prior to affections of sensibility, as being empty.

What, then, are original space and time exactly? I suggest they are, when considered as prior to affections of sensibility, merely representations that are the transcendental grounds for the possibilities for either receiving or generating actual finite spatial and temporal representations. I use the term 'transcendental' here to forestall any mistaken reading of 'grounds' as substrate manifolds of actual representations. In order to cash my position out in more detail it is necessary to consider the notions of form of intuition and formal intuition further. Before doing this, however, I must provide justification for my claim that 'form of intuition' and 'formal intuition' both refer to original space (and mutatis mutandis to original time).

Onof and Schulting have it seems to me convincingly argued (2014: 291-4) that the '[s]pace, represented as object (Gegenstand) (as is really required in geometry)', from B160-1n., is to be equated with what Kant, in his response to Abraham Kästner, calls 'metaphysical' space (cf. $R, 20: 420$ ). The argument for this is that, in his response to Kästner, Kant explains in no uncertain terms that the geometer requires precisely the representation of metaphysical space for her constructions and proofs to be possible. '[T]here are (many) spaces,' Kant writes, 'of which the geometer, in agreement with the metaphysician, must admit, as a consequence of the foundational representation of space, that they can all only be thought as parts of the unitary original space [i.e. metaphysical space]' ( $R, 20: 419)$. In a more specific example, Kant tells us that the geometer's idea of extending an actual finite line to infinity must be grounded 'on the original representation of a unitary infinite, subjectively given space [i.e. metaphysical space]' ( $R, 20: 420)$.

The terms Kant uses to describe metaphysical space are, in all important respects, the same as those he uses to describe the pure intuition of the TA. And, as I have argued above, the pure intuition of the TA is to be equated with the formal intuition of B160-1n. We are justified, then, in following Onof and Schulting in identifying the representation of space as object (which is required in geometry), from B160-1n., with the formal intuition of the same note, which is the same as the characterization of original space as pure intuition in the TA.

The justification for the claim that 'form of intuition' from B160-1n. refers to original space (and time) is much simpler. For it only needs to be noted that Kant begins his discussion of space and time in the TA by telling us that the space and time he is to discuss are 'forms of sensible intuition' (A22/B36). 
With this justification out of the way, I can now cash out my claim that original space and time, when considered as prior to affections of sensibility, are merely representations that are the transcendental grounds for the possibilities for either receiving or generating actual finite spatial and temporal representations. I will begin by considering the characterization of original space and time as forms of intuition. I suggest we understand the form of intuition as being merely a representation that defines the conditions (cf. A48-9/B65-6) for either receiving or generating spatial or temporal representations. These conditions, we can say with reference to the MEs of space and time (A23/B38ff. and A30/B46ff.), are that all received or generated spatial and temporal representations must be limited by limits of (where this means 'belonging to' or 'contained in' - after they have been received or generated) the pure/formal intuition of space (e.g. points, lines, surfaces) or limits of the pure/formal intuition of time (instants); that all received or generated spatial and temporal representations must be parts of the same unitary, unique and unlimited pure/formal intuition of space or time that metaphysically precedes them, because (to anticipate slightly) they must be actualizations of possible spaces and times 'contained' (to be discussed below) in the unitary and unlimited pure/formal intuitions of space and time; and that, as parts of the pure/formal intuitions of space and time, all received or generated spatial and temporal representations must also be intuitions.

But Kant writes at B160-1n. that 'the form of intuition merely gives the manifold'. How are we to understand this? And how do I square this with my claim, contrary to what e.g. Onof and Schulting claim, that the form of intuition does not give a manifold of actual representation? I suggest that we understand the form of intuition, considered as prior to affections of sensibility, as giving a manifold of merely possible representation. In defining the conditions for anything to be an actual spatial or temporal representation for us, all spatial or temporal representations that could be received or generated by us are given by, and with, the form of intuition as merely possible representations. An analogy may help here. Take the mathematical function $f(x)=x^{2}$. This function, we can say, defines the conditions any value would have to meet to be its output - e.g. that for any value to be its output it must be positive. We can also say, in an admittedly slightly odd turn of phrase, that as it stands the function 'gives' all positive values as merely possible outputs. When $\mathrm{x}$ takes a value, however, one of these possible outputs is actualized. Analogously, according to the position I am developing, when we receive or generate a finite, determinate spatial or temporal representation, one of the merely possible representations, one of the parts of the manifold of merely possible representation given by, and with, the form of intuition, is actualized (I will discuss the process of this actualization below).

Following on from this, I suggest we understand the formal intuition as the correlate of the conditions defined by the form of intuition, when considered as prior to affections of sensibility. This correlate, of course, is just the manifold of possible representation given by the form of intuition. ${ }^{23}$ To justify this suggestion, I need to explain how this manifold can be a pure intuition, of which spaces or times (i.e. actual spaces or times) can only be thought as parts (recall the identification of the formal intuition and the pure intuition). I will begin (counterintuitive as it may seem) with a discussion of spaces and times as parts of the manifold. According to my position, the formal intuition, considered as prior to affections of sensibility, is just the manifold of possible representation given by the form of 
intuition. We can say, then, that all temporal or spatial representations that could be actual for us are 'contained' in this manifold, in the formal intuition, considered as prior to affections of sensibility, merely as possibilities (cf. B40, B136n.). Saying this is not without textual justification. In his response to Kästner, Kant writes that in metaphysical space, which is identified as formal intuition at B160-1n., 'the possibility of all spaces, which go to infinity, is given, as singular representation' ( $R, 20$ : 42; first emphasis mine) ${ }^{24}$ Following on from this, I claim that all actual spaces and times can only be thought as parts of the manifold that is the formal intuition, according to Kant, because any actual spatial or temporal representation is just an actualization of one of the possibilities contained in the manifold of possible representation and, for this reason, it inherits the containment within the manifold of the formal intuition from the possible representation of which it is the actualization. It is, however, essential to emphasize that I am not here claiming that actual spaces and times are parts of the manifold of possible representation that is the formal intuition, when this formal intuition is considered as prior to affections of sensibility. Contrary to what e.g. Messina claims, according to my position, the formal intuition, considered as prior to affections of sensibility, contains spatial or temporal representations only as mere possibilities. What I am claiming, however, is that upon an affection of sensibility, the spatial or temporal representation that is thereby received or generated (as an actualization of a possibility) can only be thought as contained in the manifold that is the formal intuition. Upon affections of sensibility, then, the formal intuition becomes a manifold of actual and possible representations.

I will now explain how the manifold of possible representation is a pure intuition. That it is pure is clear enough. For, as the manifold of only possible representation, it is considered as prior to any affection of sensibility, meaning there can be no sensation mixed into it, which qualifies it as 'pure' for Kant (cf. A50/B74). To be an intuition, however, the manifold must also be a representation of sensibility (which it is in virtue of being the correlate of the conditions, defined by the form of intuition, for either receiving or generating representations in sensibility) and unitary (einig). That it is unitary, though, simply follows from its containing, when considered as prior to affections of sensibility, no actual spaces or times, hence no limits of space or time (e.g. points or instants). Without containing limits, the manifold of possible representation is not divided internally or set in external opposition to some other manifold of representation - it is, then, unitary (and also, it may be noted, unique). As such, the manifold of merely possible representation is a pure intuition and can thus be thought as the formal intuition of B160-1n. This properly justifies my claim, contrary to what e.g. Messina claims, that the formal intuition does not contain any actual spatial or temporal representations. Beyond this, however, it also explains why Kant writes, at B160-1n., that the formal intuition gives the unity of the representation of space that is required in geometry. The representation of space required in geometry is the representation of metaphysical space. And what gives the unity of this representation, according to my position, is just the characterization of this space as pure/formal intuition, considered as prior to affections of sensibility, i.e. as unitary manifold of merely possible representation. ${ }^{25}$

Taking both 'form of intuition' and 'formal intuition' to refer to the space and time discussed in the TA (i.e. original space and time), where the discussion is indifferent to the characterizations of space and time as forms of intuition and formal intuitions, we 
can now say, as I have suggested, that original space and time are the transcendental grounds for the possibilities for either receiving or generating actual spatial and temporal representations. What we have in the TA, according to my position, is an indifferent discussion of representations of space and time that, considered as prior to affections of sensibility, (1) define the conditions for anything to be an actual spatial or temporal representation either received or generated by us and, thereby, each give a manifold of merely possible representation (form of intuition), and (2) contain, merely as possibilities, all spatial and temporal representations that could be actual for us (formal intuition).

\section{The new proposal as sensibilist}

Thus the unity given by the formal intuition of B160-1n., which is the same as the unity of original space and time as pure intuitions, is the unity this representation has simply in virtue of its being a manifold of merely possible representation, as this means it contains no limits (see above). This unity is neither synthetic nor produced by synthesis. My position is, therefore, a sensibilist one. That being said, I must explain why, as Kant says, this unity 'presupposes a synthesis, which does not belong to the senses but through which all concepts of space and time first become possible' (B161n.).

The question that needs answering is, "what is the nature of the synthesis Kant is referring to?' Given that it is also the synthesis presupposed by the unity of the representation of space as 'object' (required in geometry), if this object were understood as a representation produced by figurative synthesis in some fashion (this could just be the figurative synthesis that realizes the OSUA), then there would be good reason to think the synthesis Kant is claiming to be presupposed is a figurative synthesis. This, however, would be problematic for my position. Figurative syntheses are enacted on sensible manifolds of actual representation. But Kant states that it is through the presupposed synthesis that 'space or time are first given as intuition' (B160n.), and my position maintains that space and time are first given as intuitions when they are considered as prior to affections of sensibility, i.e. as prior to manifolds of actual representation.

Fortunately, 'object' (Gegenstand), as Kant uses the term, need not always be understood as a representation produced by figurative synthesis. Kant's Gegenstand is the German translation of the Latin objectum and, according to Kant, 'one can, to be sure, call everything, even every representation, insofar as one is conscious of it, an object (Objecte)' (A189/B234; see also Willaschek et al. 2015: 702). Hence, 'space, represented as object' need mean nothing more than 'space, represented as a representation (i.e. pure/formal intuition) one is conscious of". This permits one to avoid understanding the synthesis Kant claims to be presupposed by the formal intuition of B160-1n. as a figurative synthesis.

In explaining what this synthesis is, I take the key to be Kant's claim that it is the synthesis that makes all concepts of space and time possible. In the TA of the B edition, even though Kant went to great pains to explain that original space and time cannot be concepts but must be intuitions (A23-5/B38-40, A30-2/B46-8), he nonetheless frames his entire discussion of the features of original space and time therein as being an exposition (Erörterung), before proceeding to state, 'I understand by exposition 
(exposition) the distinct (even if not complete) representation of that which belongs to a concept' (B38; my emphasis). He also states that, with regard to space, he will 'expound the concept of space' (B38). And, further on in CPR, he again refers to the 'pure concepts' of space and time (A156/B195). One could argue here that Kant simply made a mistake - that he meant to write 'representation' instead of 'concept'. However, I suggest that doing so blocks the most compelling understanding of the synthesis mentioned at B160-1n. ${ }^{26}$ Instead of reading Kant as having made a mistake, I take him to mean exactly what he says, that in the TA he takes it upon himself to expound the concepts of original space and time. In so doing, as I understand him, he lays out all of the conceptual marks that belong to the concepts of original space and time and finds that what these concepts represent, indifferently, are what will later come to be characterized as the form of intuition and the formal intuition of B160-1n.

With this in mind, as I read him, the synthesis that Kant claims is presupposed at B160-1n. is the synthesis of the various conceptual marks that results in the formation of the concept of original space (and mutatis mutandis original time). The reason Kant claims this synthesis to be presupposed by the unity given by the formal intuition is that it is, on his account, only by means of the concept of original space (which is formed by the synthesis at issue), that we can first think this unity. ${ }^{27}$ I take it that this is the point he is making when he writes that, through this synthesis, 'space or time are first given as intuitions' (B161n.; my emphasis). It is only due to this synthesis forming the concepts of original space and time that we can think original space and time as given as (pure/formal) intuitions. The reason Kant says this synthesis first makes all concepts of space and time possible is, as I understand him, that the a priori sciences of spaces and times are first made possible by our thinking original space and time as pure intuitions - recall the discussion of metaphysical space and geometry above. Importantly, however, because, as I have explained, the unity given by the formal intuition is neither synthetic nor produced by synthesis, it thus 'precedes all concepts' and 'belongs to space and time, and not to the concept of the understanding' and is thought as such (B160-1n.). Finally, the reason Kant says that with this synthesis the 'understanding determines the sensibility' is, as I understand him, that with this synthesis the understanding provides itself with concepts by means of which to think the faculty of sensibility through thinking original space and time as the transcendental grounds for the possibilities of either receiving or generating actual spatial and temporal representations. This synthesis determines 'the sensibility' in that it determines the representation of the faculty of sensibility by the understanding. ${ }^{28}$

\section{Conclusion: the new position as supporting a viable reading of the TD}

Original space and time, considered as prior to affections of sensibility, neither give nor contain any actual spatial or temporal manifolds. This allows me to avoid commitment to the claim I suggested was problematic for Onof and Schulting, namely, that empirical intuitions are first given in a manner such that they do not have unities produced by any synthesis that accords with the categories. My position allows for the claim that any given manifolds of actual representation are given as immediately synthesized by means of figurative syntheses, which accord with the categories. ${ }^{29}$ The proof of this claim is, of course, not given until the TD and I will not consider it here. 
That being said, I will briefly elaborate by appealing to the notion of the actualization of possible representations contained in the pure/formal intuitions. My suggestion is that we understand this actualization as occurring by means of the reception or generation, and the figurative synthesis (which occurs immediately in the case of reception), of the fundamental limits that, upon affection of sensibility, are contained in the formal intuitions of space and time, i.e. points and instants (A169/B211). It may sound odd to say that limits contained in the formal intuitions are figuratively synthesized, rather than that finite spaces and times are figuratively synthesized. However, there can be no actual finite space or time unless its limits are first synthetically unified as limits of the same representation.

This is not even close to a full reading of the TD. It does, however, support a viable reading of the TD. For the TD can now be read as presenting an argument that runs along the following lines: all actual spatial and temporal manifolds, hence all empirical intuitions, are given as immediately synthesized by figurative syntheses; figurative syntheses accord with the categories (they produce representational unities that can be subsumed under the categories); therefore, the categories have a priori validity with regard to all objects of possible experience for us.

Thus I have defended a variant of sensibilism according to which original space and time (1) neither give nor contain, when considered as prior to affections of sensibility, any manifolds of actual spatial or temporal representation, but do give and contain manifolds of merely possible spatial and temporal representation, and (2) are merely the transcendental grounds for the possibilities of receiving or generating actual spatial and temporal representations that are synthesized (immediately, in the case of reception) by figurative syntheses. This makes it possible to understand how the unities of original space and time can be neither synthetic nor produced by synthesis and how the TD of the B edition can nonetheless prove the validity of the categories with regard to all objects of possible experience for us on the basis of all empirical intuitions being given as synthesized by syntheses that accord with the categories. My proposal thus offers a rationally compelling account of Kant's conception of original space and time.

\section{Notes}

1 The translations of Kant's texts, if not my own, are from the Cambridge Edition of the Works of Immanuel Kant (Kant 1998, 2004). CPR is cited according to the standard A/B pagination. All other citations of Kant's works are by volume: page number of the Akademie Edition of Kant's works (Kant 1900ff.). I use the following additional abbreviations: $P=$ Prolegomena zu einer jeden künftigen Metaphysik (4: 255-385); $C J=$ Kritik der Urteilskraft (5: 167-485); $R=$ Zur Rezension von Eberhards Magazin Band 2 (20: 379-432). 2 I would like to thank Troy Vine and the anonymous reviewers who made helpful comments on previous versions of this article.

3 In relation to certain topics, these camps align with those that are otherwise called Conceptualists and Non-Conceptualists (see e.g. Onof and Schulting 2015 and Williams 2018), or those who favour a Synthesis and those who favour a Brute Given Reading (see Messina 2014). The reason I have chosen to adopt the proposed titles is (1) that certain intellectualists, to whom I will refer, adopt a position according to which the unities of space and time are produced by pre-conceptual synthesis, and (2) I take the debate to ultimately bear on the issue of whether the understanding (Verstand) and sensibility (Sinnlichkeit) can, in Kant's Transcendental Idealism, be understood as distinct faculties that make independent contributions to cognition. The proposed titles thus seem to both better divide the interpretative space and capture what is at stake in choosing a side. 
4 Intellectualist views are expressed by e.g. Bauer 2012, Friedman 2012, 2020, Gomes 2010, Hegel 2018, Henrich 1969, Longuenesse 1998, 2000, 2005, McDowell 2009, Pippin 1989, Paton 1936, Waxman 1991, Williams 2018. Sensibilist views are expressed by e.g. Allison 2000, 2004, Falkenstein 1995, McLear 2015, Messina 2014, Onof and Schulting 2014, 2015.

5 What I am presenting here is a general position. Nevertheless, I take it as correct to say that variants of this position have been expressed by Bauer 2012, Henrich 1969, McDowell 2009: esp. 28 and 70, Paton 1936, Pippin 1989.

6 I do not claim this is the correct reading. It is possible to read 'the pure concept of the understanding' as 'the pure concept of the entire faculty of the understanding'.

7 This is not to say that those who support this interpretation must regard the synthetic unity of a manifold of intuition as having the logical structure of a judgement.

8 For a clear articulation of a position that results from such a reading, see Henrich 1969: 646.

9 For a discussion of Kant's notion of determination, see Sutherland 2005: \$3.

10 See e.g. Keller 1998, Messina 2014, McLear 2015, Onof and Schulting 2015, Williams 2018.

11 See also Williams 2018: 73.

12 Longuenesse justifies her claim that figurative synthesis produces the formal intuitions of original space and time by noting that, at the end of the note to B160-1, Kant refers us back to $\$ 24$ of the TD, in which he discussed figurative synthesis (Longuenesse 1998: 216, 2005: 36). For my reading of the reference to $\$ 24$, see $n$. 28 below.

13 Besides the problems I will highlight here, there are also textual problems for non-categorial intellectualists. See Williams 2018 and Messina 2014.

14 This is also a major problem for categorial intellectualism.

15 Anil Gomes may also be advocating a position like Williams' when he writes, '[s]o the unity of space and time is explained in terms of the synthetic activity of the understanding: space and time stand under the synthetic unity of apperception' (2010:130). Gomes does not elaborate on the details of his position, but he also does not appeal, explicitly, to figurative synthesis.

16 Onof and Schulting are exceptions here $(2014,2015)$. They regard the discussion of original space and time as being indifferent to their characterizations as pure/formal intuitions and forms of intuition. They also regard the unity of original space and time, when characterized as pure/formal intuitions, as requiring synthesis. For this reason, it is not correct to say that they grant to original space and time everything Kant attributes to them in the MEs independently of synthesis. I will discuss their position in what follows.

17 For statements to this effect, see McLear 2015: 90, Roche 2018: 50-1, Sutherland 2005: 141.

18 As I read Kant, the term 'formal intuition' has two senses - one for pure geometrical (i.e. finite, determinate) spaces, another for the formal intuition of space mentioned at B160-1n. So while I deny that the formal intuition of B160-1n. is a determinate space, I do not thereby deny that determinate (pure geometrical) spaces are formal intuitions.

19 It is possible to read Kant here, when he writes of this unity as having been mentioned in the TA, as referring to the unity of geometrical space, which we know through synthesis. But there is no explicit statement from Kant that would favour this understanding. Moreover, in the section where he discusses geometrical space in the TA (B40-1), he does not explicitly bring up the topic of unity.

20 This position, as Onof and Schulting acknowledge (2015: 27), traces its origin back to Allison (2004) and Fichant (1997).

21 Here I simply assume that the TD involves two steps. The argument that the TD presents one argument in two steps originates in Henrich 1969.

22 Admittedly, there is a way of reading this passage such that one understands empirical intuition as first being given without having a unity produced by any synthesis that accords with the categories, but nonetheless given in a way such that it permits of being so unified. In support of such a reading, one may also point e.g. to the passage in which Kant writes, "[t]he categories of the understanding .... do not represent to us the conditions under which objects are given in intuition at all, hence objects can indeed appear to us without necessarily having to be related to functions of the understanding, and therefore without the understanding containing their a priori conditions' (A89/B122). I read Kant here as, rather, outlining the position he is intending to prove, through the TD, to be incorrect (cf. Kant 1998: 725, n. 17, added Guyer and Wood). However, I do not have the space here to present a thorough defence of this reading. I merely note that if one reads the passage just quoted as outlining Kant's considered position, 
then one cannot read the argument of the TD along the lines of 'empirical intuition is given as unified by syntheses that accord with the categories, therefore the categories have a priori objective validity'. This may not be an impossible task, but it is, I think, quite difficult. See also Roche 2018.

23 I thank Richard Aquila for suggesting this way of describing the formal intuition. In line with this description of the formal intuition, and drawing from a way of thinking about the form of intuition developed by Aquila $(2003,2016)$, the form of intuition, on my account, can be further understood in the following terms. In its defining the conditions for anything to be an actual spatial or temporal representation for us, the form of intuition, when considered as prior to affections of sensibility, grants to our faculty of sensibility an indeterminate intentional directedness, such that it is capable of determinate intentional directedness (upon affections of it) towards singular representations. The formal intuition is, then, just the correlate of this indeterminate intentional directedness.

24 Granted, in this same passage, Kant states that metaphysical space, as 'infinite, subjectively given space', contrasts with 'geometrical and objectively given space', which is always finite but potentially infinite, in that it can always be extended $(R, 20: 420)$. That is, the infinitude of metaphysical space is not to be understood (as Kästner would have it) in terms of merely possible extensions of finite geometrical space. Rather, the infinitude of metaphysical space is actual, in some sense (cf. Friedman 2020: 209). This may seem to clash with my claim that the formal intuition of space, which is what I suggest metaphysical space is identified as at B160-1n., contains only merely possible spaces. Yet, I do not deny the actual infinitude of metaphysical space. Rather, I claim that the actual infinitude of metaphysical space consists in nothing more than the formal intuition of space, considered as prior to affections of sensibility, being devoid of limits (see preceding discussion).

In his response to Kästner, Kant also states that 'a line can be drawn to infinity means so much as: the space in which I describe the line [i.e. original space] is greater than any line I may describe in it' $(R, 20$ : 420). Some interpreters have taken this to mean that the infinitude of metaphysical space consists in this 'being greater than' (cf. Carson 1997, Parsons 1992, Williams 2018). However, Kant is not writing here of what the (actual) infinitude of metaphysical space consists in but rather what the potential infinitude of the line consists in. Interpretative room is thus left open to understand metaphysical space as being greater than any line $x$ contained in it simply because, in addition to $x$, metaphysical space contains an infinitude of possible finite spaces.

25 When Kant writes that '[s]pace, represented as object ... contains ... the form of intuition' (B160n.), I understand him to mean that this space contains what is given by, and with, the form of intuition, considered as prior to affections of sensibility, i.e. the manifold of possible representation.

26 For further reasons why this move seems inappropriate, see Onof and Schulting 2015: 34.

27 It may be asked how I square my position here with the Prolegomena claim that " $\mathrm{s}$ ]pace is ... so indeterminate with respect to all specific (besonderen) properties' $(P, 4: 321)$. For if space is indeterminate with respect to properties, how can the formal intuition of space be represented by a concept? The important term here is 'specific'. In the passage in which this sentence appears, Kant is concerned with the specific properties in relation to which finite spaces are determined, such that they can be specified and distinguished from other finite spaces. What he is saying, then, is only that original space is indeterminate with respect to the specific properties of finite spaces. This does not mean we cannot represent (think) original space, or the formal intuition of space, by means of conceptual marks. Relatedly, in his response to Kästner, Kant writes that metaphysical space 'can be brought under no concept that would be capable of a construction' ( $R, 20: 420)$. All concepts capable of a construction in Kant's system, however, are geometrical concepts, i.e. concepts of finite, determinate spaces. So again, what is not ruled out is that the formal intuition of space can be brought under, and thereby thought by means of, a concept.

28 I make sense of Kant's reference, at the end of the note to B160-1, back to $\$ 24$ of the TD, where he discusses figurative synthesis, as follows. The unity produced by figurative synthesis is one that is represented in the category ('concept of the understanding'). The unity produced by figurative synthesis thus 'belongs' to the category. The reference back to $\$ 24$ signifies that the unity given by the formal intuition is not the unity produced by figurative synthesis.

29 Even though the syntheses here are immediate, they are still syntheses effected by the imagination, which coheres with Kant's statement that 'the combination (conjunction) of a manifold in general can never come to us through the senses' (B129). 


\section{References}

Allison, Henry E. (2000) 'Where have All the Categories Gone? Reflections on Longuenesse's Reading of Kant's Transcendental Deduction'. Inquiry, 43(1), 67-80.

Allison, Henry E. (2004) Kant's Transcendental Idealism. New Haven: Yale University Press.

Aquila, Richard E. (2003) 'Hans Vaihinger and Some Recent Intentionalist Readings of Kant'. Journal of the History of Philosophy, 41(2), 231-50.

Aquila, Richard E. (2016) 'Cartesian Concsiousness and the Transcendental Deduction of the Categories'. In Dina Emundts and Sally Sedgwick (eds), Internationales Jahrbuch des deutschen Idealismus, vol. 11 (Berlin: Walter de Gruyter), 3-24.

Bauer, Nathan (2012) 'A Peculiar Intuition: Kant's Conceptualist Account of Perception'. Inquiry, 55, 215-37.

Carson, Emily (1997) 'Kant on Intuition in Geometry'. Canadian Journal of Philosophy, 27(4), 489-512.

Falkenstein, Lorne (1995) Kant's Intuitionism: A Commentary on the Transcendental Aesthetic. Toronto: University of Toronto Press.

Fichant, Michel (1997) “'L'Espace est Représenté comme une Grandeur Infinie Donnée”: La Radicalité de l'Esthétique'. Philosophie, 56, 20-48.

Friedman, Michael (2012) 'Kant on Geometry and Spatial Intuition'. Synthese, 186, 231-55.

Friedman, Michael (2020) 'Space and Geometry in the B Deduction'. In Carl Posy and Ofra Rechter (eds), Kant's Philosophy of Mathematics, vol. 1: The Critical Philosophy and its Roots (Cambridge: Cambridge University Press), 200-28.

Gomes, Anil (2010) 'Is Kant's Transcendental Deduction of the Categories Fit for Purpose?'. Kantian Review, 15(2), 118-37.

Hegel, Georg Wilhelm Friedrich (2018) Hauptwerke in sechs Bänden, vol. 1. Hamburg: Felix Meiner Verlag. Henrich, Dieter (1969) 'The Proof-Structure of Kant's Transcendental Deduction'. Review of Metaphysics, 22, 640-59.

Kant, Immanuel (1900-) Kants Gesammelte Schriften. Berlin: Georg Reimer Verlag, later Walter de Gruyter.

Kant, Immanuel (1998) Critique of Pure Reason. Trans. and ed. Paul Guyer and Allen W. Wood. Cambridge: Cambridge University Press.

Kant, Immanuel (2004) Prolegomena to Any Future Metaphysics. Trans. and ed. Gary Hatfield. Cambridge: Cambridge University Press.

Keller, Pierre (1998) Kant and the Demands of Self-Consciousness. Cambridge: Cambridge University Press.

Longuenesse, Béatrice (1998) Kant and the Capacity to Judge: Sensibility and Discursivity in the Transcendental Analytic of the Critique of Pure Reason. Trans. Charles Wolfe. Princeton: Princeton University Press.

Longuenesse, Béatrice (2000) 'Point of View of Man or Knowledge of God: Kant and Hegel on Concept, Judgment, and Reason'. In Sally Sedgwick (ed.), The Reception of Kant's Critical Philosophy: Fichte, Schelling, and Hegel (Cambridge: Cambridge University Press), 253-82.

Longuenesse, Béatrice (2005) Kant on the Human Standpoint. Cambridge: Cambridge University Press.

McDowell, John (2009) Having the World in View: Essays on Kant, Hegel, and Sellars. Cambridge, MA: Harvard University Press.

McLear, Colin (2015) 'Two Kinds of Unity in the Critique of Pure Reason'. Journal of the History of Philosophy, 53(1), 72-110.

Messina, James (2014) 'Kant on the Unity of Space and the Synthetic Unity of Apperception'. Kant-Studien, 105(1), 5-40.

Onof, Christian, and Schulting, Dennis (2014) 'Kant, Kästner and the Distinction between Metaphysical and Geometric Space'. Kantian Review, 19(2), 285-304.

Onof, Christian, and Schulting, Dennis (2015) 'Space as Form of Intuition and as Formal Intuition: On the Note to B160 in Kant's Critique of Pure Reason'. Philosophical Review, 124(1), 1-58.

Parsons, Charles (1992) 'The Transcendental Aesthetic'. In Paul Guyer (ed.), The Cambridge Companion to Kant (Cambridge: Cambridge University Press), 66-100.

Paton, Herbert James (1936) Kant's Metaphysics of Experience, vol. 1. London: Allen \& Unwin.

Pippin, Robert (1989) Hegel's Idealism: The Satisfaction of Self-Consciousness. Cambridge: Cambridge University Press.

Roche, Andrew (2018) 'Kant's Transcendental Deduction and the Unity of Space and Time'. Kantian Review, 23(1), 41-64. 
Sutherland, Daniel (2005) 'The Point of Kant's Axioms of Intuition'. Pacific Philosophical Quarterly, 86, 135-59.

Waxman, Wayne (1991) Kant's Model of the Mind. Oxford: Oxford University Press.

Willaschek, M., Stolzenberg, J., Mohr, G., and Bacin, S. (eds) (2015) Kant-Lexikon. Berlin: Walter de Gruyter $\mathrm{GmbH}$.

Williams, Jessica (2018) 'Kant on the Original Synthesis of Understanding and Sensibility'. British Journal for the History of Philosophy, 26(1), 66-86.

Cite this article: Raysmith, T. (2022). Kant's Original Space and Time as Mere Grounds for Possibilities. Kantian Review 27, 23-42. https://doi.org/10.1017/\$1369415421000182 